\title{
Диффузия межузельного магния в бездислокационном кремнии
}

\author{
( В.Б. Шуман, А.А. Лаврентьев, Ю.А. Астров, А.Н. Лодыгин, Л.М. Порцель \\ Физико-технический институт им. А.Ф. Иоффе Российской академии наук, \\ 194021 Санкт-Петербург, Россия \\ E-mail: Shuman@mail.ioffe.ru
}

(Получена 10 мая 2016 г. Принята к печати 18 мая 2016 г.)

Исследовалась диффузия примеси магния в пластины монокристаллического бездислокационного дырочного кремния в диапазоне температур $T=600-800^{\circ} \mathrm{C}$. Источником диффузии служил слой, имплантированный магнием с энергией ионов 150 кэВ при дозах $5 \cdot 10^{14}$ и $2 \cdot 10^{15} \mathrm{~cm}^{-2}$. Коэффициент диффузии межузельных донорных центров магния $D_{i}$ при некоторой заданной $T$ пределялся путем измерения глубины $p-n$-перехода, который формировался в образцах, прошедших термообработку в течение времени $t$. В результате исследований впервые определена зависимость $D_{i}(T)$. Данные свидетельствуют, что диффузия осуществляется преимущественно по межузельному механизму.

DOI: 10.21883/FTP.2017.01.43986.8313

Легированный глубокой донорной примесью магния монокристаллический кремний $(\mathrm{Si}: \mathrm{Mg})$ изучался в связи с разработками детекторов для инфракрасной области спектра [1]. Известно, что кремний, содержащий мелкие доноры, может служить источником излучения в длинноволновой области спектра [2]. Поэтому интересна перспектива использовать для этих целей также и примесь магния [3]. Для получения $\mathrm{Si}: \mathrm{Mg}$ применялись различные методы: выращивание кристаллов из расплава [4], диффузия из газовой фазы в запаянной ампуле [5], жидкофазная эпитаксия [6], так называемый „сандвич-метод“ (sandwich diffusion technique) [7-9], а также ионная имплантация [10]. В работе [11] легирование кремния осуществлялось путем напыления пленки магния на поверхность образца с последующей обработкой образца импульсным лазерным излучением и высокотемпературным прогревом. Вместе с тем данные о некоторых важных для технологии $\mathrm{Si}: \mathrm{Mg}$ параметрах отсутствуют. В частности, до настоящего времени не определен коэффициент диффузии магния в кремнии.

Исследования электронного парамагнитного резонанca (ЭПР) $\mathrm{Si}: \mathrm{Mg}$ и результаты спектроскопии поглощения в инфракрасной (ИК) области [7,8] показали, что в межузельных положениях (состояния $\mathrm{Mg}_{i}$ ) примесь является двойным донором с уровнями энергии $E_{c}-0.11$ и $E_{c}-0.25$ эВ. При этом, как следует из измерений проводимости, $\mathrm{Mg}_{i}$ имеет очень низкую растворимость $\left(\sim 10^{15} \mathrm{~cm}^{-3}\right)$. В то же время полная концентрация $\mathrm{Mg}$ в кристаллах кремния, определенная атомноабсорбционным методом, может достигать $10^{19} \mathrm{~cm}^{-3}$ при $1200^{\circ} \mathrm{C}[6]$. Большую разницу между полной концентрацией и концентрацией электрически активного $\mathrm{Mg}_{i}$ авторы $[6,10]$ предложили объяснить следующим образом: находящийся в узле атом магния $\left(\mathrm{Mg}_{s}\right)$ должен быть двойным акцептором (по аналогии с $\mathrm{Zn}$ в $\mathrm{Si}$ ), поэтому возможно образование изоэлектронных пар $\mathrm{Mg}_{i}+\mathrm{Mg}_{s}$, которые не вносят вклад в проводимость.

В [10] проводились изотермические отжиги $\mathrm{Si}$ c имплантированным $\mathrm{Mg}$ в интервале температур
450-950 ${ }^{\circ}$ С. Имплантированные слои исследовались методом дифференциальной проводимости [12] и методом масс-спектроскопии вторичных ионов (ВИМС). Первый позволял определить пространственное распределение электрически активных центров $\mathrm{Mg}_{i}$, а второй полную концентрацию элемента. Было показано, что с ростом времени и температуры отжига количество электронов проводимости на см ${ }^{2}$ в имплантированном слое быстро убывает (тогда как для имплантированных примесей III и V групп эта величина, как известно, растет [13]). Исследование [10] касалось лишь имплантированного слоя полупроводника. Диффузия из этого слоя не изучалась - по-видимому, вследствие того что установка ВИМС не позволяла регистрировать концентрации магния $\lesssim 10^{17} \mathrm{~cm}^{-3}$.

Целью данной работы являлось исследование диффузии $\mathrm{Mg}$ из имплантированного слоя и определение коэффициента диффузии $\mathrm{Mg}_{i}$ в области температур $T=600-800^{\circ} \mathrm{C}$. В опытах использовались пластины толщиной 0.8 мм с ориентацией (100), вырезанные из бездислокационного $p$-Si с удельным сопротивлением 450 Ом $\cdot \mathrm{cm}$ (концентрация бора $\left.\sim 3 \cdot 10^{13} \mathrm{~cm}^{-3}\right)$, который был выращен методом зонной плавки. В пластины проводилась имплантация ионов $\mathrm{Mg}$ с энергией 150 кэВ при комнатной температуре. Были изготовлены две серии образцов с дозами облучения $F=5.0 \cdot 10^{14}$ и $2.0 \cdot 10^{15} \mathrm{~cm}^{-2}$, достаточными для аморфизации имплантированного слоя. Образцы отжигались в аргоне либо на воздухе в интервале температур $600-800^{\circ} \mathrm{C}$ при продолжительности термообработки от 5 мин до 5 ч.

На рис. 1 показаны профили распределения концентрации $\mathrm{Mg} N(d)$ в ионно-имплантированных образцах. Измерения проводились методом масс-спектроскопии вторичных ионов. В качестве зондирующих использовались ионы $\mathrm{O}_{2}^{+}$с энергией 9.5 кэВ при токе пучка 600 нА. Первичный пучок разворачивался в растр размером $500 \times 500$ мкм, в анализатор ионы поступали из центра распыляемого кратера, ограниченного областью диаметром 120 мкм для устранения вклада ионов, распылен- 


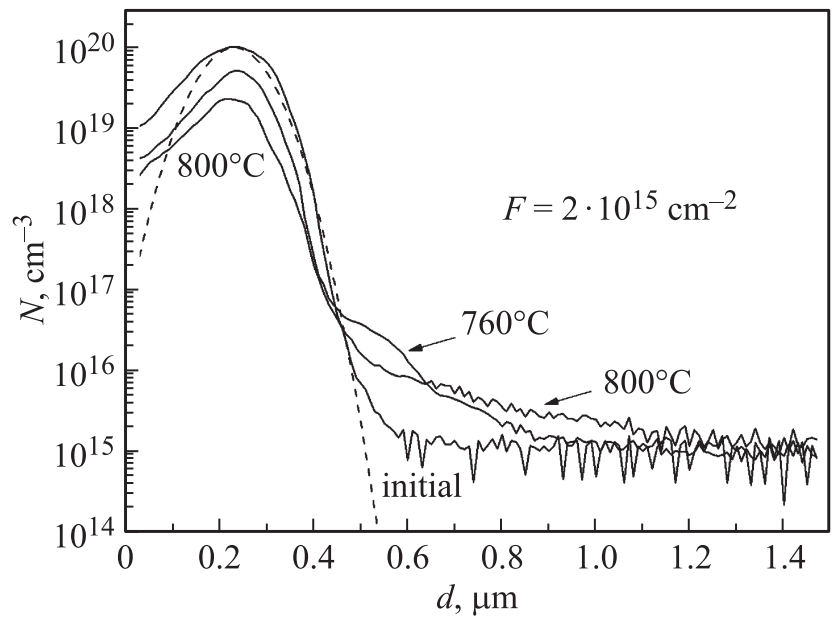

Рис. 1. Профили распределения $\mathrm{Mg}$ по глубине образца при длительности отжигов 1 ч для температур отжига 760 и $800^{\circ}$. Штриховая линия - распределение Гаусса, наилучшим образом описывающее начальное распределение примеси.

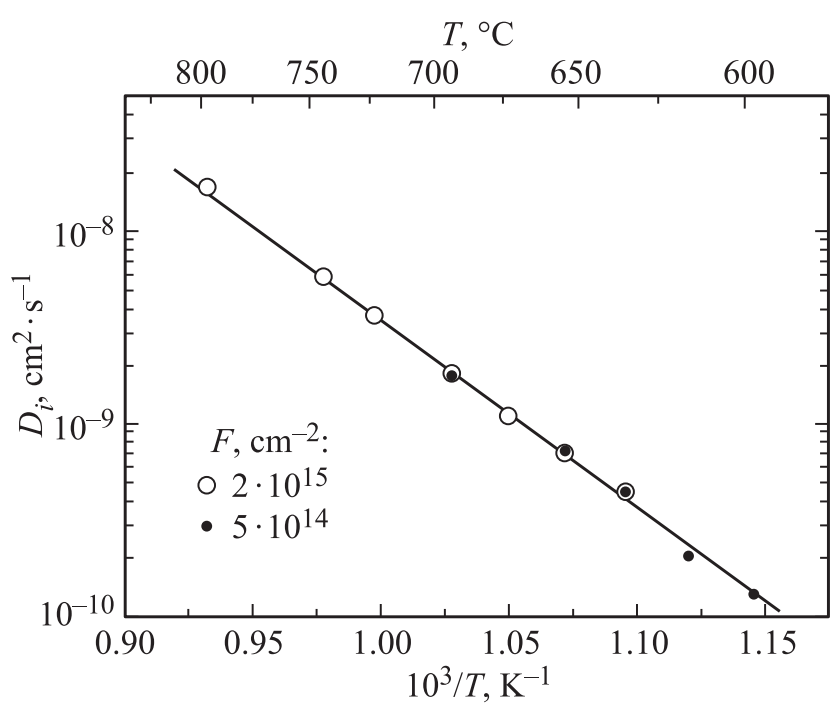

Рис. 2. Температурная зависимость коэффициента диффузии $\mathrm{Mg}_{i}$ в бездислокационном Si. Точки - эксперимент, сплошная линия - зависимость (2), полученная подгонкой уравнения Аррениуса к данным экспериментов.

ных со стенок кратера. Регистрировалась интенсивность сигналов положительных атомарных ионов. Измерения проводились в режиме послойного анализа, т. е. во время распыления образца записывалось изменение интенсивности ионного тока, соответствующего заданной массе элемента. Концентрация магния определялась путем сравнения с эталонным имплантированным стандартом. Минимальное значение концентрации $\mathrm{Mg}$, которое регистрировалось установкой, составляло $\sim 10^{15} \mathrm{~cm}^{-3}$.

Профиль распределения $\mathrm{Mg}$ в имплантированном образце, измеренный до термообработки, характеризуется средним проецированным пробегом $R_{p} \approx 230$ нм и хорошо описывается распределением Гаусса (рис. 1). На этом же рисунке представлены распределения $\mathrm{Mg}$ в образцах, которые отжигались в течение 1ч в атмосфере аргона при температурах $T=760$ и $800^{\circ} \mathrm{C}$.

В процессе отжига происходит рекристаллизация (solid phase epitaxial regrowth) аморфизованной области кремния и активация примеси $\mathrm{Mg}$. Это приводит к тому, что атомы $\mathrm{Mg}$ диффундируют из приповерхностной области в глубь кристалла. Как видно из рис. 1, максимальная концентрация примеси в области диффузионного профиля составляет $N \approx(6-8) \cdot 10^{16} \mathrm{~cm}^{-3}$.

Как известно, при рекристаллизации аморфного слоя на границе аморфного и кристаллического кремния образуется область с повышенным содержанием структурных дефектов: кластеров межузельных атомов кремния (interstitial clusters), дислокационных петель (dislocation loops) и других типов дефектов [13]. Эти дефекты могут служить центрами преципитации $\mathrm{Mg}$. Кроме того, диффузия магния происходит в условиях повышенной концентрации собственных дефектов кремния. Поэтому величина коэффициента диффузии магния в этой области может значительно отличаться от тех значений, которые этот параметр принимает в глубине кристалла.

Учитывая это обстоятельство, мы исследовали в настоящей работе коэффициент диффузии примеси $\mathrm{Mg}_{i}$ в глубине кристалла. Это было возможно благодаря тому, что имплантированный слой и лежащая ниже область образца после отжига имели $n$-тип проводимости, а проводимость более глубокой области оставалась $p$-типа. Глубина залегания $p-n$-переходов определялась с помощью метода фотозонда. При этом использовались образцы, изготовленные в виде клина с углом $4^{\circ}$ к имплантированной поверхности. Глубина перехода, измеренная таким способом, составляла от 45 до 220 мкм, в зависимости от режима отжига.

После отжига, согласно [10], распределение концентрации электронов внутри имплантированной области имеет колоколообразный вид с максимумом, который на 3-4 порядка ниже полной концентрации $\mathrm{Mg}$. Кроме того, как упоминалось выше, в [10] количество электронов в имплантированной области убывает с ростом температуры и времени отжига. Это качественно совпадает с нашими измерениями слоевого сопротивления, сделанными четырехзондовым методом на образовавшемся $n$-слое. В соответствии с этими данными проводимость слоя в результате термообработки образцов уменьшается. Поверхностная концентрация в источнике диффузии падает при этом до величин $N_{0} \leq 10^{16} \mathrm{~cm}^{-3}$. Будем полагать, что распределение $\mathrm{Mg}_{i}$ в диффузионном слое близко к гауссовому [12]. Коэффициент диффузии будем определять из выражения [12]

$$
D_{i}=\frac{x_{p-n}^{2}}{4 t \ln \left[N_{0}(t) / N_{p-n}\right]},
$$

где $t-$ время диффузии, $x_{p-n}-$ глубина залегания $p-n$-перехода, $N_{p-n}=3 \cdot 10^{13} \mathrm{~cm}^{-3}-$ концентрация межузельного $\mathrm{Mg}_{i}$ на границе $p-n$-перехода. 
На рис. 2 представлены значения коэффициента диффузии $\mathrm{Mg}_{i}$, найденные для различных температур отжига в диапазоне $T=600-800^{\circ} \mathrm{C}$; данные для образцов, полученных при дозах $F=2.0 \cdot 10^{15}$ и $5.0 \cdot 10^{14} \mathrm{~cm}^{-2}$. Прямая линия соответствует аналитической зависимости, которая получена путем подгонки уравнения Аррениуса к экспериментальным данным:

$$
D_{i}=32.0 \exp \left(-1.98 / k_{\mathrm{B}} T\right),
$$

где $k_{\mathrm{B}}-$ постоянная Больцмана, $T-$ температура (в K).

Таким образом, в настоящем исследовании определена зависимость коэффициента диффузии электрически активной примеси магния в кремнии в области температур $600-800^{\circ} \mathrm{C}$. Высокая скорость диффузии примеси указывает на то, что процесс осуществляется в основном по межузельному механизму. Отметим, что полученные данные относятся к распространению примеси в объеме бездислокационного кристалла. В приповерхностной области полупроводника скорость диффузии существенно понижена

Работа частично поддержана грантом РФФИ № 14-02-00638. Авторы благодарят Г.Я. Москалева (ОКБ-Планета, г. Великий Новгород) за проведение операции ионного легирования.

\section{Список литературы}

[1] N. Sclar. Prog. Quant. Electron., 8, 149 (1984).

[2] H.-W. Hübers, S.G. Pavlov, R.Kh. Zhukavin, V.N. Shastin. Int. J. Terahertz Sci. Technol., 7, 172 (2014).

[3] V.N. Shastin, V.V. Tsyplenkov, R.Kh. Zhukavin, K.A. Kovalevskii, Yu.A. Astrov, H.-W. Hübers, S.G. Pavlov. Proc. XVIII Symp. „Nanophysics \& Nanoelectronics“ (Nizhny Novgorod, 2014) p. 678.

[4] N.V. Abrosimov, N. Nötzel, H. Riemann, K. Irmscher, S.G. Pavlov, H.-W. Hülbers, U. Böttger, P.M. Haas, N. Drichko, M. Dressel. Sol. St. Phenomena, 131-133, 589 (2008).

[5] E. Ohta, M. Sakata. Solid-State Electron., 22, 677 (1979).

[6] H. Sigmund. J. Electrochem. Soc., 129, 2809 (1982).

[7] R.K. Franks, J.B. Robertson. Sol. St. Commun., 5, 479 (1967).

[8] L.T. Ho, A.K. Ramdas. Phys. Rev. B, 5, 462 (1972).

[9] A. Thilderkvist, M. Kleverman, H.G. Grimmeiss. Phys. Rev. B, 49, 16338 (1994).

[10] H. Sigmund, D. Weiß. In: Ion Implantation: Equipment and Techniques [Springer Series in Electrophysics, 11, (1983)] p. 473.

[11] В.М. Арутюнян, А.П. Акоян, 3.Н. Адамян, Р.С. Барсегян. ЖТФ, 71, 67 (2001).

[12] Технология СБИС, под ред. С. Зи (М., Мир, 1986) т. 1.

[13] K.S. Jones, S. Prussin, E.R. Weber. Appl. Phys. A, 45, 1 (1988).

Редактор Л.В. Шаронова

\section{Diffusion of interstitial magnesium in dislocation-free silicon}

\author{
V.B. Shuman, A.A. Lavrent'ev, Yu.A. Astrov, \\ A.N. Lodygin, L.M. Portsel \\ loffe Institute, \\ 194021 St. Petersburg, Russia
}

\begin{abstract}
The diffusion of magnesium impurity in the temperature range $T=600-800^{\circ} \mathrm{C}$ in a dislocation-free singlecrystal silicon wafers of $p$-type was studied. As a source for diffusion, served the surface layer of a wafer doped by the ion implantation technique. The implantation was carried out at the ion energy $150 \mathrm{keV}$, fluences $5 \cdot 10^{14}$ and $2 \cdot 10^{15} \mathrm{~cm}^{-2}$. The diffusion coefficient of interstitial magnesium donor centers $\left(D_{i}\right)$ was determined by measuring the depth of $p-n$-junction, which was formed in a sample due to annealing for time $t$ at a given $T$. As a result of investigation, the dependence $D_{i}(T)$ was found for the first time. The data showed that the diffusion process proceeds mainly via the interstitial mechanism.
\end{abstract}

